annual consumption of energy from all sources, $7 \%$ is from wood. In such countries as the US and the UK, less than $1 \%$ comes from wood, but in Tanzania, Nigeria, Nepal and several other countries the proportion is over $90 \%$.

The book is not difficult reading for the non-specialist as the author explains many of the basic concepts of both forestry and economics. His efforts to present ideas and data in a simple direct style, however, have resulted in a somewhat uncritical treatment.

As a source of data for discussion or decisions the book is only as good as its sources which the author acknowledges to include unreliable esti- mates. Who can record accurately the 'theft' of firewood gathered by people who regard forests as God-given and bountiful? A determined survey of consumers in one country showed that only $1.5 \%$ of fuelwood used had been recorded previously in government trade statistics.

The renewability of forests is a key point in the book. At the common yield of about 3-6 tonnes per hectare per year fuel wood production has not often been a profitable use for land. The occasional yields of eucalypt plantations of more than 40 tonnes per hectare per year on the best sites, however, are highly profitable. Can the yield be increased economically on other sites?
The current low prices of fuel wood are partly based on the wrong assumption that a forest costs nothing to grow or replace. With this assumption wood is mined, dissipating the energy capital of forests. Growing fuel wood as a crop will become a legitimate use for valuable land as the price and undesirable social costs of oil and its substitutes rise with scarcity. This is Earl's economic theme, the effects of depletion and scarcity on the price of fuel.

Earl's book may be as he says the first to assess the potential of the world's forests "as major stores and suppliers of energy". It is unlikely to be the last on this increasingly urgent subject.

Ken Eldridge

\section{Soviet geological cruises}

Rift Zones of the World Ocean. Edited by A. P. Vinogradov and G. B. Udintsev. Pp. viii+503. (Halsted Wiley: New York and Chichester; Israel Program for Scientific Translations: Jerusalem, December 1975.) $\$ 49.50 ; £ 24.75$.

DoN'T rush straight off to the bookshop, all of you eager to join in the IPOD research program. Although its title suggests a quick way of catching up on what went on in the ocean crust while you were doing your lunar rocks, this book is not that at all. First published in Moscow in 1972, with Soviet references up to 1970 , and foreign references to about 1968, this is a compilation of Soviet articles about two geological research cruises in the Indian Ocean in 1964 and 1967.

I stress the dates because it is most striking as a historical document. At that time, there was an equivocal relationship between Soviet marine geology and plate tectonics. A year or so before, diverging arrows had begun to appear on Soviet diagrams of midocean ridges, although the text was usually reticent about their precise significance. Here, the silence is profound in most of the book, most notably in the chapter on magnetics, but in the last chapter a clear acknowledgement of oceanfloor spreading as a possible process occurs both in a diagram and in the text.

Since most of the new ideas from this research have already found their way into the scientific consciousness, becoming transformed in the process, why should one buy the book? Not for its diagrams or the precision of its writing, both about par for Soviet texts. But the chapter on the 1967 seismology still looks modern, and there is one too on mineralisation in which two small sulphide-bearing rocks are described. The large collection of ultramafic rocks is well described, and there are a fair number of major element analyses, but the usefulness of the book as a quarry for data is severely reduced by the lack of any detailed positions within each polygon for the dredge stations.

I'm sure that if Gleb Udintsev and his colleagues were writing it again now, they would write it very differently, so that it is hard to recommend it enthusiastically now as a newly published book. $\quad$ J. R. Camm

\section{Bio-inorganic chemistry}

An Introduction to Bio-Inorganic Chemistry. Edited by David $\mathbf{R}$. Williams. Pp. 402. (Thomas: Springfield, Illinois, January 1976.) $\$ 24.50$.

THE preface states that this book was "conceived in a bar on Amsterdam airport by an ad hoc committee of inorganic researchers delayed by a pilots' strike". Conception in such circumstances might well be expected to produce a somewhat unselected set of characteristics in the offspring. Now that the child has been delivered we can view the baby and, mercifully, although it has the predictable blemishes, it has many endearing features. The worst blemish it shares with its parents is the wish to be too many different things, clearly shown by the section headings: bio-inorganic chemistry; instrumental approaches to bio-inorganic chemistry; biomedical applications. Taking these in turn, we might have expected first, an orderly introduction to the subject but in its place we have a jumbled set of chapters, each good in its own right, on metal complex formation, oxygen and nitrogen, iron, calcium and magnesium, and on metal- loenzymes but nothing on nucleotides sugars and membranes.

Section II is similarly disjointed. It is good on thermodynamic studies but there is no coverage of spectroscopic, magnetic, electron microscope probe methods, and so on. Bio-medical applications is a different brew but it has very little information on, for example, the effect on disease of element concentrations, although it does introduce many risky topics-for example, cancer, death, and so on (everlasting life escapes). This is a very complicated area of biological science and I am not sure that a superficial taste of some of it is not harmful or even addictive for readers never mind some of the authors.

In previous reviews of books on bioinorganic chemistry, I have pointed to the absence of material on $\mathrm{Na} / \mathrm{K} / \mathrm{Mg} /$ $\mathrm{Ca}$ metabolism. This fault is remedied in this book. I now point to another defect of conventional bio-inorganic chemistry which is strikingly apparent here-the absence of reference to the role of non-metals, $\mathbf{B}, \mathrm{Si}, \mathrm{P}, \mathrm{S}, \mathrm{Cl}$, $\mathrm{Se}, \mathrm{Br}, \mathrm{I}$, and so on. This could easily be put right in a future edition.

The overall impression given by this book is of a subject, a very large subject, in the act of growing up. Bioinorganic chemistry as seen here is beginning to receive an education. although it is still necessary for parts of it to learn their proper functions. Surely a major purpose of the book is achieved in directing attention to what inorganic chemistry is. Inorganic chemists must cease to occupy themselves with toy-rattles making noises about molecular spectroscopy and magnetism. They must again turn to the study of chemical properties. As this book shows, with its accent on enthusiasm, one big exciting area of inorganic chemistry is to be found within biology and much of importance remains to be discovered.

R. J. P. Williams 